Sociohistórica

ISSN: $1852-1606$

publicaciones@fahce.unlp.edu.ar

Universidad Nacional de La Plata

Argentina

\title{
Un consenso inestable: la cuestión de la neutralidad en la prensa y la opinión pública de Buenos Aires durante los inicios de la Gran Guerra
}

Sánchez, Emiliano Gastón

Un consenso inestable: la cuestión de la neutralidad en la prensa y la opinión pública de Buenos Aires durante los inicios de la Gran Guerra

Sociohistórica, núm. 46, 2020

Universidad Nacional de La Plata, Argentina

DOI: https://doi.org/10.24215/18521606e113

Atribución no comercial compartir igual (CC BY-NC-SA) 4.0 
Artículos

\section{Un consenso inestable: la cuestión de la neutralidad en la prensa y la opinión pública de Buenos Aires durante los inicios de la Gran Guerra}

An unstable consensus: the neutrality issue in the press and the public opinion of Buenos Aires during the beginning of the Great War

Emiliano Gastón Sánchez

DOI: https://doi.org/10.24215/18521606e113

CONICET / Universidad Nacional de Tres de Febrero

(UNTREF), Instituto de Estudios Históricos, Argentina

esanchez@untref.edu.ar

Recepción: 25 Septiembre 2019

Aprobación: 20 Diciembre 2019

Recepción: 25 Septiembre 2019

Aprobación: 20 Diciembre 2019

\section{Resumen:}

El presente artículo analiza el lugar ocupado por la cuestión de la neutralidad en la prensa y la opinión pública de Buenos Aires durante los inicios de la Gran Guerra. La campaña en defensa de la neutralidad estatal permite advertir las presiones ejercidas sobre el llamado "consenso neutralista", y las complicaciones que debió enfrentar el gobierno argentino para mantener esa posición ante la contienda. A su vez, el análisis de esta problemática, a la luz de un vasto conjunto de publicaciones periódicas, permite detectar la existencia de ciertos "usos" de la neutralidad por parte de algunos sectores de la prensa que, amparados en una supuesta defensa de los neutrales, encubrían reclamos muy sesgados contra las potencias europeas (en particular, contra Alemania) pero también como un ariete para las críticas al gobierno conservador de Victorino de la Plaza.

Palabras Clave: Gran Guerra, Neutralidad, Argentina, Prensa periódica, Opinión pública.

\section{Abstract:}

This article analyzes the place occupied by the question of neutrality in the press and public opinion of Buenos Aires during the beginning of the Great War. The campaign in defense of state neutrality lets warn the pressures exerted on the call "neutralist consensus" and the complications that the Argentine government had to face to maintain its position against the contest. At the same time, the analysis of this problem through a vast set of newspapers allows to detect the existence of certain "uses" of neutrality by some sectors of the press that, covered in a supposed defense of neutrals, covered up very biased claims against European powers (in particular, against Germany) but also for criticism of the conservative government of Victorino de la Plaza.

KEYWORDs: Great War, Neutrality, Argentine, Periodical press, Public Opinion.

La neutralidad es una vestal tan delicada que cualquier motivo pequeño é inadvertido puede violar su virginidad y colocarnos en conflicto. ${ }^{1}$

En los últimos años, el estudio de la Gran Guerra ha dejado de ser un fenómeno acotado exclusivamente a las naciones beligerantes. Como resultado de una importante renovación historiográfica, que amplió el análisis de este conflicto bélico a una escala global, algunas áreas geográficas que fueron ajenas a la contienda en términos militares pero que no por ello escaparon a sus repercusiones económicas, políticas y culturales, han adquirido un lugar cada vez más destacado en este campo de estudios. En ese marco, cabría destacar en primer lugar a las investigaciones dedicadas a los países del continente europeo (Dinamarca, España, los Países Bajos, Noruega, Suecia y Suiza) que conservaron su neutralidad durante este conflicto bélico (Van Tuyll, 2001; Abbenhuis, 2006; Amersfoort y Klinkert, 2011; Hertog y Kruizinga, 2011; Ahlund, 2012; García Sanz, 
2014; Fuentes Codera, 2014; González Calleja y Aubert, 2014; Rossfeld, Buomberger y Kury, 2014; García Sanz y Fuentes Codera, 2018). Y, en segundo lugar, a los estudios sobre las repercusiones de la Gran Guerra en los países de América Latina, neutrales en su mayoría al menos hasta la coyuntura de 1917 (Compagnon, 2014; Rausch, 2014; Garciadiego Dantan, 2017; Rinke; 2017 y Tato, 2017). ${ }^{2}$

En diálogo con estas perspectivas historiográficas, el presente artículo analiza el lugar ocupado por la cuestión de la neutralidad en la prensa y la opinión pública de Buenos Aires desde el inicio de las hostilidades hasta finales de 1914, período que delimita una primera etapa en la cobertura mediática de la conflagración marcada por su trascendencia en las páginas de la prensa y por el interés excluyente del público en estos acontecimientos. $^{3}$

Ya desde finales de julio de 1914, con el estallido de la guerra austro-serbia, el conflictivo escenario europeo adquirió una progresiva centralidad en la prensa de Buenos Aires, que se tornó casi absoluta a partir de agosto (Sánchez, 2018). Inmerso en ese clima de estupor y fascinación motivado por el estallido de la contienda, el 5 de agosto de 1914, el gobierno argentino declaró la "más estricta neutralidad" frente al estado de guerra entre "naciones amigas". ${ }^{4}$

En ese marco, al tiempo que comenzaban a bosquejarse los diferentes alineamientos ante la guerra y las simpatías por algunos de los países que participaban de la contienda, la defensa de la neutralidad adquirió un lugar importante en las páginas de la prensa local. Esta campaña de vigilancia de la neutralidad estatal permite advertir las presiones ejercidas sobre el llamado "consenso neutralista" (Compagnon, 2009, pp. 33-37 y 2014, p. 47; García Sanz y Tato, 2017, p. 117) por parte de funcionarios públicos, miembros de las fuerzas armadas y de la red diplomática y consular, pero también como un resultado indirecto del accionar de los beligerantes en la región.

Aunque esas acciones no siempre buscaban modificar la posición neutral de la Argentina ante la Gran Guerra, su abordaje revela las complicaciones que debió enfrentar el gobierno nacional para poder conservar su neutralidad y al mismo tiempo arroja una imagen menos monolítica de ese "consenso neutralista" en la prensa y la opinión pública de Buenos Aires. A su vez, el análisis de esta problemática a la luz de un vasto conjunto de publicaciones periódicas permite detectar la existencia de ciertos "usos" de la neutralidad por parte de algunos sectores de la prensa que, amparados en una supuesta defensa de los neutrales, encubrían reclamos muy sesgados contra las potencias europeas (en particular, contra Alemania) pero también como un ariete para la crítica al gobierno conservador de Victorino de la Plaza. ${ }^{5}$

\section{LA NEUTRALIDAD DEFENDIDA Y LA NEUTRALIDAD ASEDIADA}

La defensa de la neutralidad de la Argentina ante un eventual conflicto bélico en Europa contó con el rápido apoyo de un amplio sector de la prensa local. De hecho, los principales diarios de Buenos Aires se adelantaron al gobierno nacional y desde finales de julio manifestaron abiertamente la conveniencia de mantener la neutralidad ante una posible conflagración europea. En un editorial publicado al día siguiente del estallido de la guerra, La Nación propugnaba por un "patriotismo pacífico"y un giro similar fue utilizado por $E l$ Diario al afirmar que "un patriótico egoísmo ha de dirigir todas nuestras acciones. Debemos considerar la situación general desde un punto absolutamente nacional, sin ninguna referencia a intereses extraños o de conjunto" ("La catástrofe", 1914 y "Tiempos difíciles. Resoluciones extremas", 1914). Por su parte, el vespertino La Razón sostuvo que "el pueblo argentino tiene deberes que cumplir en defensa y conservación de sus propios intereses (...) La calma, la serenidad y la confianza en las propias fuerzas del país debe ser la base para establecer la regla de conducta más discreta en defensa de nuestra situación" ("Deberes populares", 1914). Días después, la firma del decreto que establecía "la más estricta neutralidad" ante la contienda europea fue ampliamente celebrado en la prensa porteña: "Permaneceros neutrales, así llegue hasta ambas dársenas la sangre de las víctimas", afirmó el diario La Mañana ("Nuestra neutralidad", 1914). 
Uno de los más tempranos y enérgicos defensores de la neutralidad estatal fue el diario La Prensa, por ese entonces uno de los periódicos más importantes de la Argentina (Sánchez, 2018, p. 183). Si bien las concentraciones que tuvieron lugar durante los primeros días de la guerra respondían más a una curiosidad del público que a un cuestionamiento de la posición oficial ante el conflicto, a medida que la opinión pública comenzaba a manifestar su apoyo y sus simpatías hacia los beligerantes, el diario de la familia Paz publicó un extenso comentario en el que pedía a la población que mantuviera la calma y, sobre todo, el respeto de la neutralidad. ${ }^{6}$ Pocos días después, y a modo de balance de la convulsiva primera semana de agosto, La Prensa demandaba a las autoridades una mayor firmeza en la defensa de la neutralidad para que "los aquí residentes, connacionales de los combatientes en Europa, no comprometan nuestra serenidad":

Una nación como la nuestra, que acoge sin reservas en su hogar a todos los trabajadores del mundo, sin hacer distinciones de nacionalidad, que recibe sangre, capitales e ideas de Francia, de Alemania, de Inglaterra, de Italia [...] en hora tan solemne como ésta no los separa, para elogiar a unos o herir a otros; observa como testigo imparcial el doloroso drama y mantiene una expectativa que nadie tiene el derecho de calificarla intencionada por unos u otros. Cuidemos nuestra serenidad, que es prenda que debemos por igual a todos los europeos que nos ayudan a enriquecer nuestra Patria y fundar su grandeza ("Juicio popular argentino", 1914).

En análogo sentido, se expresó también el vespertino La Razón en uno de sus editoriales, proponiendo la necesidad de un acompañamiento popular a la medida del gobierno, dado la cantidad de inmigrantes europeos que habitaban en Buenos Aires:

Esa neutralidad oficial, debe ser cumplimentada por la neutralidad popular, y debe, además, determinar la continencia del exhibicionismo de las pasiones exacerbadas, en los residentes que la lucha afecta, pues no deben olvidar que han solidarizado su vida con la nuestra, y á la vez, también, con la de todos los hombres de diversas nacionalidades que han llegado al país, como ellos, á la nueva vida, á la nueva labor, á los nuevos sentimientos [...] Todas las nacionalidades, todas las opiniones serán respetadas y protegidas por esta neutralidad que hemos declarado, pero si nos crea deberes antes el mundo, tenemos el derecho de exigir también que sea respetada en todo su concepto (“La neutralidad”, 1914). ${ }^{7}$

Con el correr de las semanas, esta defensa de la neutralidad estatal fue acompañada de una celosa vigilancia por parte de los principales diarios porteños. Sus recurrentes denuncias y reclamos dejan entrever no sólo el nivel de capilaridad que la repercusión de los inicios de la Gran Guerra adquirió en una ciudad lejana al conflicto como Buenos Aires, sino también las diversas presiones a las que estuvo sometido el llamado "consenso neutralista" y las dificultades del gobierno para hacer respetar su posición ante el conflicto europeo.

Uno de los primeros grupos que atrajo la atención de estos defensores de la neutralidad fueron los miembros de las Fuerzas Armadas. Durante los primeros días de la contienda, los militares fueron muy solicitados para dar cuenta de las cuestiones técnicas y estratégicas relacionadas a los movimientos de tropas en el Viejo Mundo. En ese sentido, con el doble objetivo de satisfacer la ansiedad del público y de encauzar "el comentario confuso de la multitud", La Nación entrevistó durante las primeras semanas del conflicto a una serie de oficiales de alta jerarquía del ejército argentino. "Tenía el propósito de no hablar una palabra", contestó uno de ellos, que prefirió permanecer en el anonimato, "pero confieso que no puedo negarme a una petición de 'La Nación”" ("La marcha de las operaciones. Opiniones argentinas”, 1914). No obstante, otros miembros de las fuerzas armadas, incluyendo al coronel José Félix Uriburu, director de la Escuela Superior de Guerra, publicaron diversos estudios y comentarios con su firma en el diario de la familia Mitre (Mayor Arteaga, [Francisco de], 1914; Coronel Rojas, 1914; "Los primeros combates. Opinión de un jefe argentino", 1914; Coronel Rodríguez, M., 1914; véase también Mayor Accame, 1914). Estas colaboraciones revelan una heterogénea selección por parte de La Nación que requería la opinión de figuras como Uriburu, uno de los principales responsables de la adopción del modelo prusiano en el ejército argentino (White, 1991 y García Molina, 2010) y de otros miembros de su entorno, pero también de militares como José Rojas, que habían realizado varias estancias de estudio en Bélgica. 
A la participación en la prensa se sumó también el dictado de charlas y conferencias que revelan, desde otra perspectiva, el creciente interés del público porteño por la Gran Guerra. Sin lugar a dudas, una de las más relevantes fue la conferencia impartida por el director de la Escuela Superior de Guerra, el ya citado José Félix Uriburu, el 20 de agosto de 1914 en el Ateneo Nacional, ampliamente difundida en los diarios porteños. ${ }^{8}$ Bajo el amparo de tecnicismos militares, Uriburu manifestó abiertamente sus simpatías por el ejército alemán, del cual era uno de sus principales admiradores en el ámbito local. La conferencia contó con la presencia del doctor David Peña, director de la institución organizadora, del ministro de Chile en la Argentina, Emiliano Figueroa Larrain, y del ministro de Justica e Instrucción Pública, el doctor Tomás Cullen. La asistencia al evento de un miembro del gabinete nacional motivó las críticas de algunos diarios que la consideraron como una violación de la neutralidad. Incluso ante el anuncio de la conferencia, algunos periódicos como El Tiempo habían manifestado su rechazo a que esta se realizara: “¿Puede hacerlo, estando en actividad y dado el hecho de que nuestro país es neutral? Y pudiéndolo, ¿es político que lo haga? Nuestra opinión es, que el General don José F. Uriburu no debe dar su conferencia”, afirmó el vespertino ("Conferencia y guerra”, 1914).

A pesar de estos reclamos la velada fue realizada de todos modos y, al día siguiente, las críticas apuntaron no sólo a su contenido tendencioso sino también a la presencia de un funcionario del gabinete nacional entre los asistentes a la disertación: "Cuando una asociación, cualquiera sea, costeada ó ayudada pecuniariamente por el Estado, realiza un acto público, para hacer el elogio del ejército de uno de los beligerantes, en presencia de un alto funcionario del gobierno, compromete la neutralidad del Estado", aseveró El Diario ("Deberes de la neutralidad", 1914). ${ }^{9}$ La conferencia de Uriburu fue la gota que rebalsó el vaso, y días después el Ministerio de Guerra publicó una resolución en la que prohibía a los jefes y oficiales del ejército argentino publicar en la prensa artículos relacionados con la guerra europea en los que se formularan apreciaciones que fueran más allá de lo estrictamente técnico, a la vez que recomendaba enfáticamente evitar las manifestaciones públicas de sus simpatías hacia los países beligerantes. ${ }^{10}$

Ahora bien, esta campaña en defensa de la neutralidad estatal no terminó allí pues las denuncias de los diarios alcanzaron también a los funcionarios del cuerpo diplomático y consular. Un primer episodio de estas características se produjo con motivo de un comunicado del ministro argentino en Holanda, Alejandro Guesalaga, sobre la toma de Lieja, en el cual afirmaba que los soldados belgas habían defendido el sistema de fortificaciones que rodeaba a la ciudad como "verdaderos leones". Para El Nacional, el telegrama del diplomático constituía "una evidencia de sus simpatías públicas y de sus condiciones de ardiente 'guerreiro' que olvida la discreción de su cargo y de sus deberes diplomáticos para dar rienda suelta á sus expansiones" ("Los leones de Guesalaga”, 1914). Si bien este hecho no estaba comprendido por los alcances de la legislación sobre la neutralidad aprobada en la II Conferencia de La Haya de 1907, el diario La Prensa lo consideró como una violación de la posición del Estado argentino ante la guerra y reclamó a los miembros del servicio exterior de la nación que se limitaran a transmitir la información precisa y descarnada sobre los acontecimientos, "de manera que la imparcialidad, y no la simpatía o la pasión sea el rasgo característico de sus informes" ("La neutralidad y el cuerpo diplomático argentino", 1914). ${ }^{11}$

Un segundo episodio, de mayor gravedad, se desencadenó a partir de una denuncia realizada a finales de septiembre de 1914 por el diario La Argentina, en la que afirmaba que el funcionario a cargo del consulado general argentino en Hamburgo "no cumple con sus deberes y sirve de instrumento á los planes de un gobierno sin respetar la neutralidad argentina", dado que este había enviado a Buenos Aires diferentes materiales de propaganda en favor de Alemania ("Documento comprometedor. Intervención de la Cancillería”, 1914 y "El documento comprometedor. Denuncia recogida por la Cancillería”, 1914). El documento en cuestión se trataba de un Boletín de la Guerra con noticias en castellano, que había sido enviado a las redacciones de varios diarios porteños en un sobre con membrete del consulado argentino en dicha ciudad alemana, por lo que el matutino reclamó la pronta intervención del Ministerio de Relaciones Exteriores. 
La investigación iniciada por la cartera a cargo de José Luis Murature pudo comprobar que esta denuncia era cierta. El archivo del Ministerio de Relaciones Exteriores guarda algunos de los sobres originales enviados a la redacción de El Diario y a otros particulares como el ex ministro del Interior de Roque Sáenz Peña, el doctor Indalecio Gómez; al subsecretario del Interior, el doctor Adolfo Casabal y al jefe de la División del Ministerio de Relaciones Exteriores, el señor Liborio Ponce. ${ }^{12}$ Además del señalado Boletín, los sobres contenían la edición española del Hamburger Nachrichten del 15 de septiembre y una copia mecanografiada del artículo “iAmericanos!” de la periodista Leonor Niessen Deiter, publicado en el Hamburger Tageblatt y difundido rápidamente en la Argentina a través de la red de publicaciones de la germanofilia local como la revista Ecos Gráficos y el diario La Unión (Niessen - Deiters, L., 1914 y “De la Sra. Niessen - Deiters”, 1914), el principal emprendimiento de la propaganda alemana en el país (Tato, 2018). ${ }^{13}$

A mediados de noviembre, el Ministerio dio por concluido el asunto luego de que el cónsul general Christián Sommer confesara el hecho y fuera apercibido junto con el cónsul auxiliar Francisco Scheil. En su descargo, Sommer manifestó que los envíos no tuvieron un "carácter oficial sino particular" y que buscaban "ilustrar mejor a nuestra prensa sobre los antecedentes y causas de la actual contienda (...) en vistas de las noticias erróneas publicadas por nuestros diarios" pero que jamás aspiraron a manifestar una abierta simpatía por Alemania ni mucho menos cometer una infracción a la neutralidad declarada por el gobierno. ${ }^{14}$ No obstante, el cónsul reconocía también que se había extralimitado en sus funciones al enviar la documentación a las redacciones de los diarios sin informar previamente al Ministerio.

Este no fue, sin embargo, el único caso en el que algunos funcionarios de la red consular actuaron de esta manera. De hecho, en simultaneo al incidente con el representante en Hamburgo se produjeron otros episodios similares en el viceconsulado argentino en Osnabrück, a cargo de F. Langraf, y en Frankfurt, cuyo responsable Federico Panizza integraba la comisión directiva del Servicio de Informes para los paises en idioma español y portugués, un boletín de noticias en castellano editado desde comienzos de la guerra, hecho por el que fue exonerado de su cargo a comienzos de diciembre de $1914 .^{15}$

Estos casos, que la prensa porteña siguió con atención denunciando una y otra vez la pasividad del gobierno nacional, ${ }^{16}$ revelan la existencia de circuitos alternativos para la llegada de la propaganda germanófila a Buenos Aires. Y al mismo tiempo, dejan en evidencia la precariedad de la estructura consular argentina durante los primeros meses de la Gran Guerra, dada la tendencia a contratar para los cargos consulares a súbditos y ciudadanos de los países europeos, los cuales ocasionarían un grave problema para la neutralidad argentina. En este sentido, sin dudas, el caso más extremo se produjo con el fusilamiento por las tropas alemanas del vicecónsul argentino en la ciudad belga de Dinant, Remy Himmer, que colocó al gobierno conservador frente al primer conflicto diplomático de gravedad (Martin, 1967, p. 186; Weinmann, 1994, pp. 55-56; Cisneros y Escudé, 1999, pp. 167-168; Lanús, 2001, pp. 65-67; Compagnon, 2014, pp. 47-48; Rinke, 2017, p. 54).

Ahora bien, lo destacable desde el punto de vista de la campaña de la defensa de la neutralidad es que, una vez concluida la investigación llevada a cabo por el gobierno nacional, este episodio motivó la suspensión definitiva de los cónsules que pertenecían a los países que intervenían en la conflagración. Por ello, el 28 de noviembre de 1914, el presidente De la Plaza firmó un primer decreto que suspendía provisoriamente en sus funciones a varios vicecónsules de nacionalidad de países beligerantes, y dos días después decretóla suspensión definitiva en sus funciones consulares, y hasta nueva resolución, de todos los vicecónsules argentinos de nacionalidad extranjera radicados en Alemania, Austria-Hungría, Bélgica, Francia, Inglaterra, Italia, Portugal y Rusia. ${ }^{17}$ En total, fueron 55 los funcionarios afectados y 45 los viceconsulados cerrados por la aplicación de estas nuevas medidas (Solveira, 1997, p. 159).

Continuando con esa campaña en defensa de la neutralidad desde las páginas de la prensa, cabría señalar que la Gran Guerra conmovió a tal extremo a la sociedad porteña que, al parecer, varios profesores de colegios públicos de la ciudad de Buenos Aires usaron las aulas como tribunas para lanzar sus opiniones sobre la contienda europea. Este hecho motivó una temprana resolución del Ministerio de Instrucción Pública que 
prohibía terminantemente las opiniones en clase sobre el conflicto bélico. Según el diario Tribuna, dicha resolución era un acto de defensa de la neutralidad pero también una salvaguarda de la "juventud estudiosa" que tiende a ser "poco reflexiva y se deja arrastrar por ímpetus peligrosos" ("Resolución acertada”, 1914). No obstante, las opiniones de los profesores parecen haber continuado luego de esta normativa y, tras recibir algunas denuncias al respecto, el diario La Prensa dirigió un nuevo llamado de atención al ministro de Instrucción Pública sobre los docentes que opinaban en clase sobre la contienda europea, "haciendo comentarios en pro y en contra de los beligerantes y aduciendo causas y derechos favorables a los de su simpatía personal o de la nacionalidad de sus antepasados, así como vaticinios y aún votos por el resultado de la guerra" (“Comentarios imprudentes”, 1914).

Los intentos por contener las posibles violaciones de la neutralidad motivaron también un decreto del intendente municipal Joaquín Samuel de Anchorena que prohibió a los teatros, cafés cantantes y cinematógrafos, la representación de toda obra y la exhibición de cintas que "por su lenguaje, acciones o argumentos pudieran provocar (...) manifestaciones de cualquier género en favor ó en contra de las naciones ó pueblos extranjeros” afectados por el conflicto (Sánchez, 2018, pp. 193-194). La decisión fue impulsada por las reiteradas interrupciones y algunas riñas entre los asistentes a La hija del tambor mayor, una opereta de Jacques Offenbach que narraba las peripecias del ejército napoleónico en el norte de Italia a comienzos del siglo XIX y en cuyo acto final sonaba el himno revolucionario Le chant du départ (1794) mientras un grupo de soldados marchaba enarbolando la bandera tricolor.

Sin embargo, estos diferentes decretos y resoluciones administrativas fueron transgredidos con bastante frecuencia a lo largo de la guerra, dejando en evidencia las dificultades del gobierno para mantener la neutralidad incluso entre los funcionarios y empleados de la administración pública. A estos reclamos particulares podrían agregarse también otros más radicales en defensa de la neutralidad como, por ejemplo, los pedidos del diario El Tiempo para que se impidiera la salida de los reservistas europeos, las manifestaciones en favor de los bandos en disputa, la venta de boletines ligados a las colectividades extranjeras en las calles de Buenos Aires y su rechazo al subsidio otorgado por el Concejo Deliberante de la capital al Comité Pro Bélgica, con el objeto de socorrer a los niños huérfanos por la guerra. ${ }^{18}$

\section{LOS USOS DE LA NEUTRALIDAD}

Ahora bien, si como se ha visto hasta ahora la declaración de la neutralidad no se tradujo en una limitación a este tipo de acciones por parte de los funcionarios públicos, tampoco implicó la emergencia de un clima de Union Sacrée ni de Burgfrieden que limitara las críticas al gobierno nacional ante un escenario complejo e inestable. Por el contrario, la ausencia de restricciones a la palabra impresa hizo que la Gran Guerra fuera tempranamente utilizada como un insumo para atacar a la administración conservadora de Victorino de la Plaza.

Las críticas al gobierno apuntaron sobre todo a las repercusiones económicas del conflicto bélico y a su incapacidad para contener las consecuencias de lo que un colaborador de la revista Caras y Caretas llamó "la guerra sin sangre", es decir, la disputa entre las potencias europeas por los recursos económicos que, a nivel local, se tradujo en una importante crisis económica y social (Montesa, 1914).

Pocas horas después del estallido de la contienda, Victorino de la Plaza, el vicepresidente a cargo de la presidencia de la nación desde octubre de 1913 por la enfermedad de Roque Saénz Peña, convocó el domingo por la tarde a una reunión de gabinete en su domicilio particular en la que se decidieron una serie de medidas que buscaban contener las posibles complicaciones económicas y financieras ocasionadas por la guerra. El paquete de medidas incluía un decreto de feriado cambiario y bancario del 3 al 8 de agosto, una moratoria interna por treinta días, el cierre de la Caja de Conversión, la autorización a la Caja de Conversión a redescontar documentos comerciales del Banco de la Nación, facultar a las legaciones para recibir el pago 
en oro de los deudores de firmas argentinas para luego remitirlo al país y la prohibición de exportar oro, trigo y harina (Weinmann, 1994, pp. 39-41).

Si bien este paquete de medidas contó con el apoyo de un amplio sector de la prensa, el decreto del feriado bancario fue una decisión alarmante y problemática para la inmensa mayoría de la sociedad porteña y ocasionó el temor a una posible corrida bancaria (Sánchez, 2018, pp. 190-191). La falta de arribos de los buques europeos sumada a la prohibición de exportar trigo y maíz desde la Argentina provocaron una virtual paralización del puerto de Buenos Aires que impulsó la desocupación y el aumento en los precios de los alimentos y los combustibles (Rinke, 2017, pp. 71-72). ${ }^{19}$

Tanto el gobierno nacional como el municipal pusieron en marcha algunas medidas con el objeto de paliar los efectos de la crisis como, por ejemplo, la organización de ollas populares en diferentes barrios de Buenos Aires y el alojamiento de los desocupados en el Hotel de Inmigrantes. Incluso algunos sectores de la prensa y del periodismo porteño hicieron su aporte solidario en esa crítica coyuntura: así, durante todo el mes de septiembre de 1914 el semanario Fray Mocho distribuyó unas seis mil raciones de comida entre las mujeres y los niños, mientras que el dibujante Oñiverta lanzó a sus colegas la propuesta de organizar un Salón de Caricaturistas a beneficio de los menesterosos. ${ }^{20}$

No obstante, estas medidas no lograron mitigar las críticas contra un gobierno "inesperado" y al mando de una figura sobre la que no se cifraban grandes expectativas. ${ }^{21}$ Las diatribas de la prensa periódica apuntaron inicialmente a la excesiva pasividad del gobierno ante los problemas económicos causados por el conflicto bélico. "Al fin, parece que nuestro gobierno se ha orientado de una manera definitiva", afirmaba irónicamente una portada del semanario Caras y Caretas de mediados de septiembre en la que todos los miembros del gabinete nacional caminaban a tientas y con los ojos vendados ("Tardío, pero seguro", 1914).

Con frecuencia, esos ataques adquirieron también un tono personal contra el presidente de la república, representado como un hombre mayor, entrado en kilos y poco afecto al trabajo ("La labor de un presidente", 1914). Según una ilustración de José María Cao, publicada como portada del semanario Fray Mocho (Figura 1), para Victorino de la Plaza la neutralidad consistía en comer de todo un poco: "pan de Viena, caviar ruso, cerveza alemana, rosbif a la inglesa, repollitos de Bruselas, kaki japonés y champagne legítimos. ¡Esta es la verdadera neutralidad!" (Cao, 1914). ${ }^{23}$

Ahora bien, la inestabilidad de ese "consenso neutralista" fue también una consecuencia directa de las acciones de las potencias beligerantes en el territorio argentino. Ante todo, cabe señalar las recurrentes denuncias de la prensa sobre la existencia de estaciones radiotelegráficas clandestinas que operaban en favor de Alemania. Al comienzo de la guerra, Gran Bretaña había cortado el único cable submarino que conectaba a Alemania con el continente americano, forzándola a utilizar la radiotelegrafía para sus comunicaciones con Sudamérica (Sánchez, 2014b, pp. 64-65). En ese marco, el Estado argentino sometió el flujo de las comunicaciones radiográficas a la órbita del Ministerio de Marina y mediante una serie de decretos y circulares trató de vigilar las comunicaciones realizadas por los buques extranjeros en sus aguas territoriales. En primer lugar, se prohibió el uso de códigos secretos en las transmisiones telegráficas internacionales y la utilización de estaciones de radio en los buques de países beligerantes en aguas argentinas. La operación de clausura de las estaciones radiotelegráficas de los buques se llevaba a cabo al momento de arribar al puerto mediante una faja sellada, comprobándose luego, a la salida de aguas territoriales que los sellos puestos por la Prefectura estuvieran intactos. Y, en segundo lugar, se exigió a los barcos de bandera argentina que navegasen por el Río de la Plata que sus radiooperadores fuesen argentinos y que operaran en presencia de un funcionario del gobierno nacional ${ }^{24}$. Este ministerio fue el encargado de atender las mencionadas denuncias sobre la existencia de estaciones radiotelegráficas clandestinas que violaban la neutralidad argentina en favor de Alemania. Amparadas en una defensa de la neutralidad, este tipo de reclamos, realizados por algunos de los diarios alineados más claramente con los aliados de la Entente, buscaban instalar en el seno de la opinión pública cierta psicosis sobre la presencia del espionaje alemán en Buenos Aires. ${ }^{25}$ 
Otro de los hechos que motivó los reclamos de la prensa fue la supuesta violación de la neutralidad por parte de los buques alemanes que, inescrupulosamente, cargaban el máximo de carbón posible en el puerto neutral de Buenos Aires, a pesar de que un decreto del gobierno nacional había establecido al carbón como un producto de contrabando, por lo que su acopio quedaba limitado al mínimo indispensable para arribar al puerto de destino. ${ }^{26}$

No obstante, en estas denuncias públicas, que iban acompañadas de fuertes reclamos al gobierno nacional de una mayor vehemencia en el control de este tipo de acciones, era más relevante el hecho de que esas supuestas violaciones de la neutralidad fueran producidas por buques y agentes alemanes que la defensa de la neutralidad en sí misma. En sentido contrario, el diario La Unión realizó la misma operación denunciando la violación de la neutralidad por parte de los buques de bandera inglesa y la forma despectiva de Inglaterra en el trato con las repúblicas sudamericanas (“Se hace la luz", 1914). De esta manera, la defensa de la neutralidad en las páginas de la prensa de Buenos Aires durante los primeros meses de la Gran Guerra emerge como una posición sutilmente disputada por algunos diarios como La Argentina que, en rigor, encubrían reclamos muy sesgados contra los enemigos de la Triple Entente.

Otros ejemplos de cómo estas simpatías por los países en pugna se resguardaban detrás de una supuesta defensa de la neutralidad pueden verse en los comentarios en torno a las acciones navales en el Atlántico Sur. En primer lugar, la llegada a Buenos Aires de los marinos alemanes del transatlántico Cap Trafalgar, un buque perteneciente a la compañía Hamburgo-Sudamérica armado como crucero auxiliar en el inicio de la guerra, y hundido el 14 de septiembre por su par británico, el Carmania (Newton, 1977, p. 41; Rinke, 2017, p. 50 y Champenois, 2018, pp. 24-27). A finales de ese mes, arribaron al puerto de Buenos Aires, bajo la atenta mirada de los reporters y fotógrafos de la prensa local, los 278 sobrevivientes que habían sido rescatados en alta mar por el buque Eleonore Woermann. ${ }^{27}$ Los heridos fueron trasladados al Hospital Alemán mientras que el resto de la tripulación fue confinada en la isla Martín García, de acuerdo con lo establecido por la II Conferencia de la Haya de 1907. Poco tiempo después, la colectividad alemana de Buenos Aires, a través de la sociedad Germania, organizó una visita a la isla en la que participaron también varios cronistas y fotógrafos de la prensa porteña. ${ }^{28}$

A comienzos de diciembre, comenzó a circular un rumor sobre la fuga de algunos oficiales que se encontraban detenidos en la isla. Los comentarios de los diarios en torno a este suceso ilustran cabalmente las tensiones y solapamientos entre la defensa de la neutralidad y un sentimiento de hostilidad hacia Alemania, cada vez más extendido en el seno de la opinión pública local. Según una primera versión, la fuga había sido protagonizada por ocho oficiales que utilizaron una canoa para adentrarse en el Río de la Plata, donde los esperaba el Eleonore Woermann ("La fuga de los oficiales alemanes. Un asunto grave”, 1914). No obstante, la investigación oficial confirmó que se trataba de sólo tres detenidos: los fogoneros Reimer Tuil y Kurth Difieu (o Dilfleu), y el zapatero Eichhoren Anton, que habían utilizado una canoa para dirigirse rumbo a la costa uruguaya ("En Martín García. Los marinos alemanes”, 1914 y "Los escapados de Martín García”, 1914).

La confirmación de la fuga motivó las críticas de algunos diarios porteños contra Alemania, considerado como el único país europeo que "ha violado e intenta violar nuestra neutralidad, cargando buques con carbón y víveres para sus buques de guerra (...) tiene estaciones radiotelegráficas clandestinas y sólo él también intenta en otras formas equivalentes comprometernos en su favor dentro del pleito europeo" "Consecuencias de la debilidad. Respetos al neutral”, 1914). Incluso algunos periódicos simpatizantes de los aliados de la Entente como La Argentina acusaron a la colectividad alemana de Buenos Aires de tener participación directa y complicidad con la fuga pues, según ciertas versiones, en una de las visitas a la isla habían viajado entre los excursionistas algunos marinos mercantes que cambiaron sus trajes con los oficiales de la armada germánica allí confinados. De esta manera, "los oficiales germánicos pudieron escapar á la reclusión que padecían, venir á Buenos Aires y salir de nuestro puerto en barcos mercantes para incorporarse de nuevo á la armada imperial" ("Evasión de marinos alemanes de la isla Martín García”, 1914 y “Como en 'la Gran Vía”, 1914). 
Sólo el diario La Unión trató de minimizar el episodio, considerado como una exageración de los sectores más afines a los aliados, embanderados en una falsa defensa de la neutralidad:

El hecho en sí no tiene importancia, puesto que son tres humildes obreros que tratarán de ganarse el pan con su labor diaria en la vecina república en vez de comer el que le brindaba nuestro gobierno sin exigir trabajo alguno; pero no falta quienes ven en este insignificante suceso, un hecho que puede perjudicar grandemente la causa de los aliados. Nosotros, en primer lugar, no podemos figurarnos cómo harán esos hombres para llegar a las filas alemanas y en segundo, qué influencia mágica podrían tener esos tres personajes para salvar la causa germana (“Tres nombres célebres”, 1914).

Como puede verse, entonces, los problemas ocasionados por la reclusión de los marinos alemanes del Cap Trafalgar en aguas territoriales argentinas pusieron en entredicho la pretensión de mantener "la más absoluta neutralidad" ante un conflicto bélico cuyas repercusiones globales tornaban absurda dicha empresa.

En segundo lugar, cabría mencionar también la exaltada celebración de la batalla de las Islas Malvinas, que tuvo lugar el 8 de diciembre de 1914 en al Atlántico sur. El episodio naval que antecedió a este combate, ocurrido a finales de octubre en el Cabo Coronel perteneciente a aguas territoriales chilenas, desató las quejas de varios diarios que vieron en ello una violación de la neutralidad del país trasandino. ${ }^{29}$ Sin embargo, pocas semanas después, la victoria de la armada inglesa en el combate de las Malvinas fue abiertamente festejada por un sector de la prensa porteña pues, a su juicio, la destrucción de la escuadra alemana liberaba el océano Atlántico de los peligros para el comercio argentino. El diario La Argentina, por ejemplo, un activo defensor de la neutralidad cuando los implicados en esas supuestas violaciones eran buques alemanes, celebraba el aniquilamiento de la flota germana como un hecho que despejaba el Atlántico sur de "los buques corsarios que paralizaron durante mucho tiempo nuestro comercio marítimo con Europa”, considerado como un acto más de la prepotencia alemana contra un país sudamericano, ajeno a la guerra y cuya economía dependía en buena medida del comercio exterior ("El Atlántico libre. Derrota de la escuadra alemana", 1914). ${ }^{30}$ Posteriormente, la llegada al puerto de Montevideo del Invencible, uno de los buques británicos que habían intervenido en el combate, contó con una amplia cobertura por parte de la prensa porteña; incluso algunos diarios como Crítica enviaron a sus reporters a la capital uruguaya con el objetivo de obtener más información sobre este enfrentamiento. $^{31}$

Del mismo modo, muchos de los diarios que se autoproclamaron como celosos defensores de la neutralidad mantuvieron un suspicaz silencio frente a otros actos que también podían interpretarse como una violación de la posición estatal. Es el caso de la venta de caballos, ponchos y yerba mate para los ejércitos de la Triple Entente, operaciones comerciales en las cuales al Estado argentino actuó como un intermediario, facilitando las gestiones para los exportadores locales. ${ }^{32}$ Lejos de toda crítica, dichas compras fueron celebradas por buena parte de los diarios de Buenos Aires. El vespertino La Razón, por ejemplo, consideraba a estas adquisiciones como un gran avance para la "industria nacional" y, sobre todo, como un triunfo del "criollismo", equiparable al éxito del tango en las grandes metrópolis europeas:

Ya no es sólo el éxito inesperado y colosal del tango en los salones europeos, lo que debe alabar nuestra vanidad criolla, ya que
para muchos el triunfo de la música orillera no resultaba una grata expresión del espíritu argentino. Hoy, la guerra, ha venido á
enseñarnos otros campos de actividad en que las cosas ó costumbres criollas empiezan a predominar en la progresista Europa.
Los ejércitos piden caballos criollos para sus marchas penosas; compran yerba para ofrecer á sus soldados el mate reparador
y lubrificante del paisano y, por último, solicitan el poncho erigido desde ahora en el mejor y más conveniente abrigo para
los ejércitos en campaña. Esto sin contar con el trigo y la carne, productos de América, que constituyen la base alimentación
para sus pueblos y fuerzas; decididamente, América triunfa sobre el cuadro europeo y en especial nuestro país, lo que no deja
de ser una grande é inmediata satisfacción para nosotros ("En los ejércitos europeos. Triunfo del criollismo", 1914). ${ }^{33}$

Como puede apreciarse, el tono es más bien de un cierto orgullo nacional ante la posibilidad de insertar en el mercado europeo esos productos arquetípicos, y ajeno a todo cuestionamiento de la injerencia de un Estado neutral en esas transacciones. En este sentido, uno de los pocos periódicos que, al menos fugazmente, percibió esta contradicción fue el diario Tribuna que en un artículo de comienzos de octubre, se preguntaba: 
¿Cómo apreciará el gobierno alemán las nuevas relaciones económicas que se inician con la Francia, al proveerla nosotros de elementos para la guerra, que en tal carácter debe conceptuarse la provisión de paños y frazadas adquiridas, teniendo en cuenta la neutralidad declarada por nuestro gobierno? Menester parécenos que el Poder Ejecutivo se preocupe en resolver previamente el problema, fijándose de antemano la norma de conducta a seguir (...) ¿No sería este negocio motivo para una protesta análoga a la anterior, de Inglaterra, sobre el aprovisionamiento de carbón a un vapor alemán que desapareció misteriosamente de nuestro puerto? ("Industrias nacionales", 1914).

Sin embargo, sólo algunas semanas después este mismo diario exhibía un tono similar al del vespertino $\mathrm{La}$ Razón al comentar una fotografía de "un gallardo soldado inglés sonriendo bajo la protección segura de un fino poncho americano”, que había sido publicada en Caras y Caretas,y la noticia de que el ejército inglés planeaba introducir el maté como infusión para sus soldados en reemplazo del tradicional té. ${ }^{34}$

La postura más consistente sobre este tema provino del diario La Tarde, que a finales de noviembre denunció en un editorial la intervención del Ministerio de Agricultura en la adquisición de caballos para los ejércitos beligerantes como un acto que implicaba una flagrante violación de la neutralidad infringida por un organismo del mismo Estado nacional en beneficio de los estancieros: “ $¡ T$ Todo un ministerio nacional convertido en intermediario entre compradores y estancieros! $i$ Todo un gobierno que se echa sobre su frente el estigma de la parcialidad (...) no cabe otro recurso que solicitar de la Academia Española que borre la palabra 'neutralidad' del diccionario de la lengua castellana”, afirmó el vespertino a comienzos de diciembre ("Neutralidad discutible", 1914).

Como era de esperar, esta postura crítica fue acompañada por el diario La Unión según el cual la visión de la neutralidad como un amparo para comerciar con todas las naciones implicaba en los hechos un beneficio que sólo alcanzaba a los aliados de la Triple Entente (“¿Nuestra neutralidad?”, 1914). La medida motivó incluso la publicación de una "Carta abierta al Presidente de la República" en el Argentinisches Tageblatt, uno de los principales periódicos de la colectividad alemana en Argentina, que consideraba a la venta de caballos para Francia como una "violación incontrovertible" de la neutralidad estatal y que además, lejos de hacerse en secreto, era abiertamente festejada en las páginas de los principales diarios del país ${ }^{35}$.

Estos episodios de intermediación del Estado en la venta de productos argentinos que podrían considerarse como contrabando de guerra constituyen en cierto sentido un antecedente de la llamada "neutralidad benévola" de Hipólito Yrigoyen, asociada a la firma en 1918 de un convenio para el aprovisionamiento de cereales en condiciones muy ventajosas para Francia y Gran Bretaña (Weinmann, 1994, pp. 141-143; Cisneros y Escudé, 1999, pp. 101-103). Al mismo tiempo, esta defensa de la neutralidad por parte de la prensa porteña revela también cierto solapamiento con una mirada más optimista sobre el papel de la Argentina y América que emerge al calor del nuevo escenario europeo (Compagnon, 2014, pp. 16-17 y Sánchez, 2014a, pp. 132-146).

\section{CONSIDERACIONES FINALES}

La Argentina fue uno de los países del continente americano que mantuvo su neutralidad ante la Gran Guerra durante todos los años que duró el conflicto bélico. No obstante, este hecho no impidió que la prensa y la opinión pública de Buenos Aires hayan tomado a la cuestión de la neutralidad como un eje central en las discusiones que siguieron al estallido de la guerra. El análisis de la campaña en defensa de la neutralidad estatal permitió advertir las presiones ejercidas sobre el llamado "consenso neutralista" por parte de diferentes actores locales, pero también como consecuencia del accionar de los beligerantes en la región.

Aunque esas acciones no siempre buscaban modificar la posición oficial de la Argentina frente a la Gran Guerra, su abordaje reveló los diversos obstáculos que debió enfrentar el gobierno de Victorino de la Plaza para conservar una neutralidad porosa, frágil y delicada, como la vestal a la que hace alusión el pasaje que encabeza este artículo. 
Y, a su vez, el abordaje de esta problemática a la luz de un vasto conjunto de publicaciones periódicas dejó en evidencia la existencia de ciertos "usos" de la neutralidad por parte de algunos sectores de la prensa que, amparados en una supuesta defensa de los neutrales, encubrían reclamos muy sesgados contra las potencias europeas, tomándolos también como un ariete para ejercer las críticas a la incapacidad del gobierno argentino por contener las repercusiones económicas y sociales ocasionadas por la conflagración europea.

\section{FUENTES PRIMARIAS (DOCUMENTOS INÉDITOS, PERIÓDICOS, MEMORIAS Y LIBROS)}

Archivo del Ministerio de Relaciones Exteriores y Culto, República Argentina, Sección Primera Guerra Mundial. Caja AH0002, "Guerra europea. Alemania".

Archivo del Ministerio de Relaciones Exteriores y Culto, República Argentina, Sección Primera Guerra Mundial. Caja AH0016, "Guerra europea. Medidas de Guerra. Neutralidad".

Arhivo del Ministerio de Relaciones Exteriores y Culto, República Argentina, Sección Primera Guerra Mundial. Caja AH0026, "Guerra europea. Funcionarios argentinos".

Archivo del Ministerio de Relciones Exteriores y Culto, Republica Argentina, Sección Primera Guerra Mundial. Caja AH0027, "Guerra europea. Beligerantes en la República Argentina".

Archivo General de la Nación, Fondo Victorino de la Plaza. Legajo N. 418, "Documentación oficial y particular"(octubre de 1914)

¿Dónde está el gobierno? (1 de septiembre de 1914). El Diario. Diario de la tarde, p. 4.

¿Nuestra neutralidad? (18 de noviembre de 1914). La Unión. Diario de la tarde, p. 5.

A la buena de Dios. (16 de octubre de 1914). El Diario. Diario de la tarde, p. 4.

Asunto del cónsul de Hamburgo. Reiteración de la solicitud de informes. (6 de octubre de 1914). La Razón. Diario de la tarde, p. 1.

Ateneo Nacional. Conferencia del general Uriburu. (21 de agosto de 1914). La Gaceta de Buenos Aires. Diario de la tarde, p. 3.

Ateneo Nacional. Conferencia sobre la guerra. (19 de agosto de 1914). El Pueblo. Diario de la mañana, p. 3.

Ateneo Nacional. La conferencia de anoche. (21 de agosto de 1914). La Prensa. Diario de la mañana, p. 6.

Cao, J. M. Ecuánime. (11 de septiembre de 1914). Fray Mocho. Semanario festivo, literario, artístico y de actualidades, $\mathrm{s} / \mathrm{p}$.

Comentarios imprudentes. (31 de agosto de 1914). La Prensa. Diario de la mañana,p. 8.

Como en 'la Gran Vía'. (8 de diciembre de 1914). La Mañana. Diario noticioso e independiente, p. 1.

Cómo fue el combate naval de las Malvinas. Brillante recepción á los marinos victoriosos en Montevideo. (21 de diciembre de 1914). La Argentina. Primer diario moderno de la mañana, independiente e impersonal, p. 1.

Conferencia interesante. (19 de agosto de 1914). La Gaceta de Buenos Aires. Diario de la tarde, p. 5

Conferencia sobre la guerra. (29 de agosto de 1914). P.B.T. Semanario ilustrado (para niños de 6 a 80 años), s/p.

Conferencia y guerra. (20 de agosto de 1914). El Tiempo. Diario de la tarde, p. 1.

Conferencias. 'La contienda europea'. (20 de agosto de 1914). La Nación. Diario de la mañana, p. 6.

Consecuencias de la debilidad. Respetos al neutral. (9 de diciembre de 1914). La Gaceta de Buenos Aires. Diario de la tarde, p. 1.

Consulados argentinos. (17 de diciembre de 1914). El Nacional. Diario de la tarde, p. 7.

Consulados suprimidos. (17 de diciembre de 1914). El Pueblo. Diario de la mañana, p. 2.

Cónsules argentinos beligerantes. (30 de octubre de 1914). El Tiempo. Diario de la tarde, p. 1.

Coronel Rodríguez, M. (14 de agosto de 1914). La Gran Guerra. Hipótesis y comentarios. La Nación. Diario de la mañana, p. 5. 
Coronel Rojas, J. A. (7 de agosto de 1914). La invasión alemana de Bélgica. El plan defensivo. La Nación. Diario de la mañana, p. 5.

Corresponsales diplomáticos. (23 y 24 de agosto de 1914). El Diario. Diario de la tarde, p. 1.

De la Sra. Niessen - Deiters. La información europea en América.(4 de noviembre de 1914). La Unión. Diario de la tarde, p. 4.

De la Sra. Niessen - Deiters. La información europea en América. (5 de noviembre de 1914). La Unión. Diario de la tarde, pp. 6-7.

Deberes de la neutralidad. (25 de agosto de 1914). El Diario. Diario de la tarde, p. 4.

Deberes ineludibles en militares y particulares. (25 de agosto de 1914). La Prensa. Diario de la mañana,p. 9.

Deberes populares. (3 de agosto de 1914). La Razón. Diario de la tarde, p. 4.

Desconcierto general. (3 de septiembre de 1914). El Diario. Diario de la tarde, p. 4.

Documento comprometedor. Intervención de la Cancillería. (28 de septiembre de 1914). La Argentina. Primer diario moderno de la mañana, independiente e impersonal, p. 1.

Ecos del combate en las Malvinas. El 'Invencible' en Montevideo. (21 de diciembre de 1914). La Prensa. Diario de la mañana, p. 6.

Efectos de la guerra en nuestro país. Las estaciones radiográficas en los buques de bandera argentina. (10 de diciembre de 1914). La Argentina. Primer diario moderno de la mañana, independiente e impersonal, p. 5.

El Atlántico libre. Derrota de la escuadra alemana. (10 de diciembre de 1914). La Argentina. Primer diario moderno de la mañana, independiente e impersonal, p. 4.

El combate naval en las Malvinas. Nuevos detalles de la acción. Partida del 'Invencible'. (22 de diciembre de 1914). La Nación. Diario de la mañana, p. 5.

El cónsul argentino en Hamburgo. (7 de octubre de 1914). El Nacional. Diario de la tarde, p. 1.

El documento comprometedor. Denuncia recogida por la Cancillería. (29 de septiembre de 1914). La Argentina. Primer diario moderno de la mañana, independiente e impersonal, p. 1.

El nuevo presidente. (12 de agosto de 1914). La Gaceta de Buenos Aires. Diario de la tarde, p. 1.

El problema financiero. (12 de septiembre de 1914). La Mañana. Diario noticioso e independiente, p. 1.

El triunfo del poncho criollo. (28 de octubre de 1914). La Argentina. Primer diario moderno de la mañana, independiente e impersonal, p. 6.

En el Ateneo Nacional. (21 de agosto de 1914). La Tarde, p. 2.

En el Ateneo Nacional. Conferencia del general Uriburu. (19 de agosto de 1914). La Razón. Diario de la tarde, p. 5.

En el Ateneo Nacional. Conferencia del general Uriburu. (21 de agosto de 1914). La Razón. Diario de la tarde, p. 4.

En los ejércitos europeos. Triunfo del criollismo. (2 de octubre de 1914). La Razón. Diario de la tarde, p. 1.

En Martín García. Los marinos alemanes. (8 de diciembre de 1914). La Prensa. Diario de la mañana, p. 9

Enviado especial. The most opportune victory. El buque almirante 'Invencible' en Montevideo. El corresponsal especial de CRÍTICA fue el único periodista que tuvo acceso a la nave de guerra inglesa. (21 de diciembre de 1914). Critica. Diario ilustrado de la noche, impersonal e independiente, p. 3.

Evasión de marinos alemanes de la isla Martín García. (8 de diciembre de 1914). La Argentina. Primer diario moderno de la mañana, independiente e impersonal, p. 5.

Flagrante violación de la neutralidad argentina. (16 de octubre de 1914). La Argentina. Primer diario moderno de la mañana, independiente e impersonal, p. 5.

Fray Mocho en Montevideo. El combate de las Malvinas. (25 de diciembre de 1914). Fray Mocho. Semanario festivo, literario, artístico y de actualidades, $\mathrm{s} / \mathrm{p}$.

Hermosa iniciativa. Actitud de un caricaturista. (8 de septiembre de 1914). La Tarde, p. 1.

Industrias nacionales. (10 de octubre de 1914). Tribuna. Diario de la tarde, p. 1.

Informaciones oficiales. Diplomáticos en ridículo. (22 de agosto de 1914). La Tarde, p. 1. 
Instalaciones radiotelegráficas. Los alemanes en Buenos Aires. (31 de octubre de 1914). Critica. Diario ilustrado de la noche, impersonal e independiente, p. 4.

Juicio popular argentino. (7 de agosto de 1914). La Prensa. Diario de la mañana, p. 8.

La catástrofe. (2 de agosto de 1914). La Nación. Diario de la mañana, p. 7.

La conferencia. (21 de agosto de 1914). El Tiempo. Diario de la tarde, p. 1.

La conflagración europea. Fueron conducidos ayer á la isla Martín García los tripulantes del Cap Trafalgar. (28 de septiembre de 1914). La Argentina. Primer diario moderno de la mañana, independiente e impersonal, p. 5.

La diplomacia argentina. Cónsules y vicecónsules beligerantes. (28 de noviembre de 1914). La Tarde, p. 1.

La escuadra británica en Montevideo. (26 de diciembre de 1914). Caras y Caretas. Semanario Festivo, Literario, Artístico y de Actualidad, s/p.

La falsa neutralidad. (24 de octubre de 1914). La Argentina. Primer diario moderno de la mañana, independiente e impersonal, p. 4.

La fuga de los oficiales alemanes. Un asunto grave. (6 y 7 de diciembre de 1914). El Diario. Diario de la tarde, p. 11.

La gloriosa tradición de Nelson. Dignamente continuada. (13 de noviembre de 1914). La Argentina. Primer diario moderno de la mañana, independiente e impersonal, p. 5.

La guerra en las costas sudamericanas. Los heridos del Cap Trafalgar. (2 de octubre de 1914). Fray Mocho. Semanario festivo, literario, artístico y de actualidades, $\mathrm{s} / \mathrm{p}$.

La Guerra Europea. Conferencia del general Uriburu. (21 de agosto de 1914). La Argentina. Primer diario moderno de la mañana, independiente e impersonal, p. 5.

La inactividad del puerto. (12 de septiembre de 1914), P.B.T. Semanario ilustrado (para niños de 6 a 80 años), s/p.

La labor de un presidente. (18 de diciembre de 1914). Critica. Diario ilustrado de la noche, impersonal e independiente, p. 1.

La manufactura nacional. (12 de octubre de 1914). La Prensa. Diario de la mañana, p. 4.

La marcha de las operaciones. Opiniones argentinas. (8 de agosto de 1914). La Nación. Diario de la mañana, p. 10.

La miseria en Buenos Aires. La olla de 'FRAY MOCHO'. (11 de septiembre de 1914), Fray Mocho. Semanario festivo, literario, artístico y de actualidades, $\mathrm{s} / \mathrm{p}$.

La miseria en Buenos Aires. Socorro a los menesterosos. La contribución de 'Fray Mocho'. (4 de septiembre de 1914). Fray Mocho. Semanario festivo, literario, artístico y de actualidades, s/p.

La neutralidad argentina y la sudamericana. (5 de diciembre de 1914). La Razón. Diario de la tarde, p. 3.

La neutralidad en peligro. (4 de noviembre de 1914). La Gaceta de Buenos Aires. Diario de la tarde, p. 3.

La neutralidad y el cuerpo diplomático argentino. (10 de agosto de 1914). La Prensa. Diario de la mañana, p. 7.

La neutralidad. (7 de agosto de 1914). La Razón. Diario de la tarde, p. 4.

La tragedia del Cap Trafalgar. (3 de octubre de 1914).P.B.T. Semanario ilustrado (para niños de 6 a 80 años), s/p.

Llegada de la escuadra inglesa á Montevideo. (21 de diciembre de 1914). La Mañana. Diario noticioso e independiente, p. 6.

Los desocupados del puerto. (15 de octubre de 1914). La Razón. Diario de la tarde, p. 6.

Los efectos de la guerra. (1 de agosto de 1914). La Nación. Diario de la mañana, p. 8.

Los escapados de Martín García. (8 de diciembre de 1914). El Diario. Diario de la tarde, p. 1.

Los leones de Guesalaga. (11 de agosto de 1914). El Nacional. Diario de la tarde, p. 2.

Los marinos alemanes en Martín García. La visita de ayer. (10 de noviembre de 1914). La Unión. Diario de la tarde, p. 7.

Los militares argentinos y la guerra europea. (22 de agosto de 1914). El Diario. Diario de la tarde, p. 1.

Los militares argentinos y la guerra. Sus publicaciones en la prensa. (22 de agosto de 1914). La Razón. Diario de la tarde, p. 1.

Los náufragos del Cap Trafalgar. Confinados en Martín García. (28 de septiembre de 1914). La Prensa. Diario de la mañana, p. 6. 
Los náufragos del Cap Trafalgar. En Martín García. La excursión de ayer. (9 de noviembre de 1914). La Prensa. Diario de la mañana, p. 8.

Los primeros combates. Opinión de un jefe argentino. (7 de agosto de 1914). La Nación. Diario de la mañana, p. 11. Los reservistas. (6 de noviembre de 1914) El Tiempo. Diario de la tarde, p. 1.

Los sobrevivientes del Cap Trafalgar. Actitud del gobierno argentino. (27 y 28 de septiembre de 1914). El Diario. Diario de la tarde, p. 4.

Los sobrevivientes del Cap Trafalgar. Serán confinados en Martín García. (27 de septiembre de 1914). La Mañana. Diario noticioso e independiente, p. 4.

Mate y poncho. (13 de noviembre de 1914). Tribuna. Diario de la tarde, p. 3.

Mayor Accame. (14 de agosto de 1914). El ejército francés frente al alemán. Ligera ojeada del probable desarrollo de las operaciones militares en la actual guerra. La Mañana. Diario noticioso e independiente, p. 1

Mayor Accame. (15 de agosto de 1914). El ejército francés frente al alemán. La Mañana. Diario noticioso e independiente, p. 1.

Mayor Arteaga, [Francisco de]. (3 de agosto de 1914). La Triple Alianza y la Triple Entente. El plan de guerra. La Nación. Diario de la mañana, p. 4.

Militares, publicistas y oradores. (24 de agosto de 1914). El Tiempo. Diario de la tarde, p. 1.

Montesa, G. La guerra sin sangre. (5 de septiembre de 1914). Caras y Caretas. Semanario Festivo, Literario, Artístico y de Actualidad, s/p.

Neutralidad argentina. (6 de agosto de 1914). El Tiempo. Diario de la tarde, p. 1.

Neutralidad argentina. Negligencia del gobierno. (17 de octubre de 1914). La Argentina. Primer diario moderno de la mañana, independiente e impersonal, p. 4.

Neutralidad discutible. (10 de diciembre de 1914). La Tarde, p. 1.

Niessen - Deiters, L. ¡Americanos! (noviembre de 1914). Ecos Gráficos, pp. 405-408.

Nuestra neutralidad. (15 de octubre de 1914). La Gaceta de Buenos Aires. Diario de la tarde, p. 5.

Nuestra neutralidad. (6 de agosto de 1914). La Mañana. Diario noticioso e independiente, p. 1.

Nuestros cónsules en Alemania. (7 de octubre de 1914). Crítica. Diario ilustrado de la noche, impersonale independiente, p. 4 .

Nuestros militares y la guerra. Resolución del ministerio. (23 de agosto de 1914). La Mañana. Diario noticioso e independiente, p. 12.

Propaganda en favor de Alemania. El consulado de Hamburgo. (5 y 6 de octubre de 1914). El Pueblo. Diario de la mañana, p. 3.

Publicaciones militares sobre la guerra. (23 de agosto de 1914). La Nación. Diario de la mañana, p. 8.

Radiografía clandestina. (24 de octubre de 1914). La Tarde, p. 1.

Reorganización de la diplomacia. (6 de octubre de 1914). Tribuna. Diario de la tarde, p. 1.

Resolución acertada. (10 de agosto de 1914). Tribuna. Diario de la tarde, p. 1

Rimac. La paralización en el puerto. (6 de noviembre de 1914). Fray Mocho. Semanario festivo, literario, artístico y de actualidades, $\mathrm{s} / \mathrm{p}$.

Se hace la luz. (23 de noviembre de 1914). La Unión. Diario de la tarde, p. 7.

Subsidio a los belgas. Un error. (21 de noviembre de 1914). El Tiempo. Diario de la tarde, p. 1.

Tardío, pero seguro. (19 de septiembre de 1914). Caras y Caretas. Semanario Festivo, Literario, Artístico y de Actualidad, s/p.

Tareas del gobierno. (5 de agosto de 1914). La Razón. Diario de la tarde, p. 5.

Tiempos difíciles. Resoluciones extremas. (1 de agosto de 1914). El Diario. Diario de la tarde, p. 4.

Tres nombres célebres. (12 de diciembre de 1914). La Unión. Diario de la tarde, p. 5.

Una conferencia del General Uriburu. (21 de agosto de 1914). La Mañana. Diario noticioso e independiente, p. 4. 
Una conferencia interesante. En el Ateneo Nacional. (15 de agosto de 1914). La Mañana. Diario noticioso e independiente, p. 6.

Velando por nuestra neutralidad. Comprobación de las denuncias de 'La Argentina'. (21 de octubre de 1914). La Argentina. Primer diario moderno de la mañana, independiente e impersonal, p. 2.

Vicecónsules argentinos extranjeros. Cesación de funciones. (28 de noviembre de 1914). La Prensa. Diario de la mañana, p. 7.

Vigil, C. C. La semana. (23 de septiembre de 1914). Mundo Argentino. Semanario popular ilustrado, s/p.

Violación de la neutralidad. El Diario. Diario de la tarde, (19 de diciembre de 1914), p. 1.

Violando la neutralidad. (20 de noviembre de 1914), El Tiempo. Diario de la tarde, p. 1.

Violando la neutralidad. El cónsul de Frankfurt. (6 de octubre 1914). La Argentina. Primer diario moderno de la mañana, independiente e impersonal, p. 4.

Violando la neutralidad. Oficina radiográfica clandestina. (23 de octubre de 1914). La Argentina. Primer diario moderno de la mañana, independiente e impersonal, p. 5.

Visita a los marinos del ‘Cap Trafalgar' en Martín García. (14 de noviembre de 1914). Caras y Caretas. Semanario Festivo, Literario, Artistico y de Actualidad, s/p.

Ministerio de Marina (1915). Memoria del Ministerio de Marina correspondiente al ejercicio 1914-1915. Buenos Aires: Imprenta J. Weiss \& Preusche.

Ministerio de Relaciones Exteriores y Culto (1919). Documentos y actos de gobiernos relativos a la guerra en Europa. Buenos Aires: Ministerio de Relaciones Exteriores y Culto.

Ibarguren, C. (1977). La historia que he vivido. Buenos Aires: Biblioteca Dictio.

\section{BiBLIOGRAFÍA SECUNDARIA}

Abbenhuis, M. (2006). The Art of Staying Neutral: The Netherlands in the First World War, 1914-1918. Amsterdam: Amsterdam University Press.

Ahlund, C. (2012). Scandinavia in the First World War: studies in the war experiences of the Northern neutrals. Suecia: Nordic Academic Press.

Amersfoort, H. y Klinkert, W. (2011). Small powers in the age of total war, 1900-1940. Amsterdam: Brill.

Carreras, S. (2008). ¿Cómo circulan los saberes? La relación intelectual entre Leonore Deiters, Ernesto Quesada y Oswald Spengler. Politicas de la memoria. Anuario de investigación e información del CeDInCI, 8/9, 221-230.

Champenois, G. (2018). La neutralidad imposible: historias argentinas de la Primera Guerra Mundial. Buenos Aires: Olmo Ediciones.

Cisneros, A. y Escudé, C. (Dirs.) (1999). Historia general de las relaciones exteriores de la República Argentina, parte II, t. VIII, "Las relaciones con Europa y los Estados Unidos, 1881-1930". Buenos Aires: Nuevohacer.

Compagnon, O. (2014). América latina y la Gran Guerra. El adiós a Europa (Argentina y Brasil, 1914-1939). Buenos Aires: Crítica.

Compagnon, O. (2009). Entrer en guerre? Neutralité et engagement de l'Amérique latine entre 1914 et 1918. Relations Internationales, 137, 31-43.

Fuentes Codera, M. (2014). España en la Primera Guerra Mundial. Una movilización cultural. Madrid: Akal.

Garciadiego Dantan, J. (Coord.) (2017). Elmundo hispanoamericano y la Gran Guerra. Ciudad de México: El Colegio de México.

García Molina, F. (2010). La prehistoria del poder militar en la Argentina: la profesionalización, el modelo alemán y la decadencia del régimen oligárquico. Buenos Aires: Eudeba.

García Sanz, C., y Fuentes Codera, M. (2018). Los combates por la neutralidad en la Gran Guerra: una propuesta desde el caso español. En D. Alegre, M. Alonso y J. Rodrigo (Coords.), Europa desgarrada: guerra, ocupación y violencia, 1900-1950 (pp. 137-162). Zaragoza: Prensas de la Universidad de Zaragoza. 
García Sanz, C., y Tato, M. I. (2017). Neutralist crossroads: Spain and Argentina facing the Great War. First World War Studies, 8(2-3), 115-132. DOI: https://10.1080/19475020.2017.1385407

García Sanz, F. (2014). España en la Gran Guerra: espias, diplomáticos y traficantes. Barcelona: Galaxia Gutemberg.

González Calleja, E. y Aubert, P. (2014). Nidos de espias. España, Francia y la Primera Guerra Mundial, 1914-1919. Madrid: Alianza.

Hertog, J. y Kruizinga, S. (2011). Caught in the Middle. Neutrals, neutrality and the First World War. Amsterdam: Aksant Academic Publishers/Amsterdam University Press. Lanús,

Lanús, J. A. (2001). Aquél apogeo. Política internacional argentina, 1910-1939. Buenos Aires: Emecé.

McNally, M. (2012). Coronel and Falklands 1914. Duel in the South Atlantic. Oxford: Osprey Publishing.

Martin, P. A. (1967). Latin America and the War. Massachusetts: Peter Smith.

Newton, R. (1977). German Buenos Aires, 1900-1933: Social Change and Cultural Crisis. Austin y Londres: University of Texas Press.

Rausch, J. M. (2014). Colombia and World War I: the experience of a neutral Latin American nation during the Great War and its aftermath, 1914-1921. Maryland: Lexintong Books.

Rinke, S. (2017). Latin America and the First World War. Nueva York: Cambridge University Press.

Rossfeld, R., Buomberger, T., y Kury, P. (2014). 14/18: La Suisse et la Grande Guerre. Baden: Hier + Jetzt.

Sánchez, E. G. (2018). Pasión de multitudes: la prensa y la opinión pública de Buenos Aires frente al estallido de la Gran Guerra. Anuario IEHS, 33(1), 177-204.

Sánchez, E. G. (2014a). La prensa de Buenos Aires ante 'el suicidio de Europa'. El estallido de la Gran Guerra como una crisis civilizatoria y el resurgimiento del interrogante por la identidad nacional. Memoria y Sociedad. Revista de Historia, 18(37), 132-146

Sánchez, E. G. (2014b). Pendientes de un hilo. Guerra comunicacional y manipulación informativa en la prensa porteña durante los inicios de la Gran Guerra. Política y Cultura. Revista Académica del Departamento de Política y Cultura,42, 55-87.

Solveira, B. (1997). La Evolución del Servicio Exterior Argentino entre 1852 y 1930. Córdoba: Centro de Estudios Históricos.

Tato, M. I. (2018). Fighting for a Lost Cause? The Germanophile newspaper La Unión in Neutral Argentina, 1914-1918. War in History, 25(4), 464-484.

Tato, M. I. (2017). La trinchera austral. La sociedad argentina ante la Primera Guerra Mundial. Rosario: Prohistoria. Van Tuyll, H. (2001). The Netherlands and World War I. Espionage, Diplomacy and Survival. Leiden: Brill.

Vázquez-Presedo, V. (1971). El caso argentino. Migración de factores, comercio exterior y desarrollo, 1875-1914.Buenos Aires: Eudeba.

Weinmann, R. (1994). Argentina en la Primera Guerra Mundial: neutralidad, transición política y continuismo económico. Buenos Aires: Biblos-Fundación Simón Rodríguez.

White, E. B. (1991). German influence in the Argentine army, 1900 to 1945. Nueva York: Garland Publishing.

\section{Notas}

1 "Neutralidad", 1914. Se han conservado la ortografía y la puntuación originales en las citas de las fuentes primarias.

2 Si bien la neutralidad fue la opción más elegida a comienzos de la Gran Guerra, esa posición sólo fue mantenida hasta la firma del armisticio por la Argentina, Chile, Colombia, El Salvador, México, Paraguay y Venezuela. El resto de los países del continente ingresó en la guerra en apoyo a los Estados Unidos o al menos rompió relaciones diplomáticas con Alemania con motivo de la guerra submarina ilimitada (Rinke, 2017, p. 123).

3 A finales de ese año, el estancamiento de los frentes dio por tierra la ilusión de los contemporáneos de pasar la "Navidad en casa" y tiñó con un signo trágico los diversos balances de fin de año de la prensa de Buenos Aires. Ese escenario abrió paso a una nueva etapa en la cobertura periodística de este evento global en el que la prensa porteña debió realizar nuevos esfuerzos para atraer y conservar la atención de sus lectores en torno a la guerra. 
4 Durante la administración conservadora de Victorino de la Plaza, entre la firma del primer decreto y el 31 de agosto de 1916, esta posición fue reafirmada en ocho oportunidades, a medida que se incorporaban nuevas potencias europeas al conflicto. Archivo del Ministerio de Relaciones Exteriores y Culto, República Argentina, Sección Primera Guerra Mundial (en adelante, AMREC-PGM), caja AH0016, "Guerra europea. Medidas de Guerra. Neutralidad”, legajos II 1-8. Los decretos pueden consultarse también en el llamado Libro Azul, publicado por el gobierno argentino luego de la firma del armisticio, Documentos y actos de gobiernos relativos a la guerra en Europa, Buenos Aires, Ministerio de Relaciones Exteriores y Culto, 1919, pp. 3-33.

5 El corpus de fuentes utilizado en este artículo excluye a la prensa socialista y anarquista y a la prensa de las colectividades extranjeras radicadas en la Argentina, las cuales como ha señalado Stefan Rinke (2017, pp. 46-47) también presionaron sobre la neutralidad oficial. No obstante, por tratarse de un nicho específico (aunque no estanco) de la opinión pública local, tanto la prensa étnica como la prensa de las izquierdas requieren de un análisis específico y pormenorizado.

6 "La conflagración europea ha conmovido el espíritu popular. Por todas partes, dondequiera se reúnan dos hombres, el tema de los comentarios es el de la guerra entre Alemania y Francia, el cálculo de probabilidades sobre cuál de las dos naciones resultará vencedora, las complicaciones financieras y económicas, etcétera, etc.". "Juicio popular argentino", 1914. Por su parte, La Nación afirmó que "conviene reprimir el arrastre a una situación de pánico que en realidad existe por ahora tan sólo en los espíritus en excitación sobreaguda, pero no en los hechos concretos". "Los efectos de la guerra”, 1914.

7 Cabe recordar que en vísperas de la Gran Guerra aproximadamente el $30 \%$ de los habitantes del país eran extranjeros, un porcentaje que trepaba hasta el $50 \%$ en la ciudad de Buenos Aires. Según los datos del Tercer Censo Nacional, realizado en junio de 1914, el grueso de la población extranjera se repartía entre las siguientes colectividades: italianos (40,6 \%), españoles $(36,3 \%)$, rusos $(4,1 \%)$, franceses $(3,5 \%)$, sirio-libaneses $(2,8 \%)$, austro-húngaros $(1,7 \%)$, británicos $(1,2 \%)$, alemanes $(1,1 \%)$ y suizos (0,6\%). (Vázquez-Presedo, 1971, p. 94).

8 "Una conferencia interesante. En el Ateneo Nacional”, 1914; “Ateneo Nacional. Conferencia sobre la guerra", 1914; "Conferencia interesante”, 1914, "En el Ateneo Nacional. Conferencia del general Uriburu”, 1914; "Conferencias. 'La contienda europea”, 1914; "La Guerra Europea. Conferencia del general Uriburu”, 1914; “Ateneo Nacional. Conferencia del general Uriburu”, 1914; “Ateneo Nacional. La conferencia de anoche”, 1914; "Una conferencia del General Uriburu”, 1914; "En el Ateneo Nacional. Conferencia del general Uriburu”, 1914; "Conferencia sobre la guerra”, 1914.

9 En el mismo sentido véase también: “La conferencia”, 1914 y “En el Ateneo Nacional”, 1914.

10 "Los militares argentinos y la guerra europea”, 1914; "Los militares argentinos y la guerra. Sus publicaciones en la prensa", 1914; "Nuestros militares y la guerra. Resolución del ministerio", 1914; "Publicaciones militares sobre la guerra", 1914; "Militares, publicistas y oradores", 1914 y “Deberes ineludibles en militares y particulares", 1914.

11 Véanse también las críticas a la publicación en la prensa de información procedente del cuerpo diplomático y consular en "Corresponsales diplomáticos", 1914 e "Informaciones oficiales. Diplomáticos en ridículo", 1914.

12 AMREC-PGM, caja AH0026, "Guerra europea. Funcionarios argentinos”, legajo II E1. Indalecio Gómez también se había desempeñado como ministro plenipotenciario en Europa central durante la presidencia de Manuel Quintana y era un abierto partidario de Alemania, aunque se privó de hacer públicas sus simpatías en los medios locales. No obstante, según relata Carlos Ibarguren en sus memorias (1977, p. 443), el ex ministro participó durante la guerra de varias veladas en la legación alemana de Buenos Aires. En septiembre de 1915, entrevistado en la capital argentina por el corresponsal del Berliner Tageblatt, Gómez se declaró un “amigo de Alemania” y atribuyó la actitud de la prensa y la opinión pública porteña al accionar de las agencias de noticias aliadas y al desconocimiento general de "ese pueblo preeminente", lo que había abonado las fantasías del "peligro alemán” en Sudamérica. Una copia de este reportaje puede consultarse en AMREC-PGM, caja AH0002, “Guerra europea. Alemania”, legajo I A 4, fs. 156-161. Sobre el papel de las agencias de noticias europeas en la construcción de una imagen peyorativa de Alemania durante los inicios de la contienda (Sánchez, 2014).

13 Leonor Niessen Deiters fue una periodista alemana, corresponsal en Sudamérica del Koelnische Zeitung y la segunda esposa de Ernesto Quesada. Ambos se conocieron en septiembre de 1913, cuando Niessen Deiters le realizó una entrevista en Buenos Aires a su padre Vicente. Al estallar la guerra, Leonor le solicitó a Ernesto Quesada su colaboración en la defensa de Alemania ante la opinión pública sudamericana y este se comprometió con esa misión, publicando varios artículos en Buenos Aires, algunos de los cuales llegarían al Koelnische Zeitung por intermedio de la periodista. Ese vínculo que inicialmente estuvo sostenido en su naturaleza intelectual y cimentado por intereses comunes adquirió luego un tono amoroso y en 1919, finalizada la guerra, Niessen Deiters viajó a Buenos Aires y se unió a Quesada (Carreras, 2008, pp. 222-224).

14 AMREC-PGM, caja AH0026, legajo II E1, fs. 10-12 y 17-19.

15 AMREC-PGM, caja AH0026, legajo II E1, fs. 29-31 y 32-38. 
16 Véanse, entro otras, "Propaganda en favor de Alemania. El consulado de Hamburgo", 1914; "Violando la neutralidad. El cónsul de Frankfurt", 1914; "Reorganización de la diplomacia”, 1914; "Asunto del cónsul de Hamburgo. Reiteración de la solicitud de informes", 1914; "Nuestros cónsules en Alemania”, 1914; "El cónsul argentino en Hamburgo", 1914; "Cónsules argentinos beligerantes", 1914.

17 AMREC-PGM, caja AH0038, “Guerra europea”, legajos II O. La diplomacia argentina. Cónsules y vicecónsules beligerantes. (28 de noviembre de 1914). La Tarde, p. 1; Vicecónsules argentinos extranjeros. Cesación de funciones. (28 de noviembre de 1914). La Prensa, p. 7; Consulados suprimidos. (17 de diciembre de 1914). El Pueblo, p. 2 y Consulados argentinos. (17 de diciembre de 1914). El Nacional, p. 7. Los decretos posteriores se firmaron el 31 de mayo de 1915, el 8 de septiembre de 1915, el 17 de febrero de 1916 y el 31 de marzo de ese año.

18 Véase, respectivamente, "Neutralidad argentina", 1914; "Los reservistas", 1914; "Violando la neutralidad, 1914 y Subsidio a los belgas. Un error, 1914.

19 Véanse también las crónicas "La inactividad del puerto", 1914; "Los desocupados del puerto", 1914 y Rimac, 1914.

20 La revista Fray Mocho otorgó vales canjeables por comida a través de diversas comisarías de la ciudad y contó con el apoyo de la Escuela Internacional de Cocina y Pastelería que solía anunciar en el semanario. "La miseria en Buenos Aires. Socorro a los menesterosos. La contribución de 'Fray Mocho", 1914 y "La miseria en Buenos Aires. La olla de 'FRAY MOCHO”, 1914. Sobre la propuesta de Oñiverta: “Hermosa iniciativa. Actitud de un caricaturista”, 1914.

21 "De vice que fue [De la Plaza] ha pasado a ser titular por un aciago escamoteo del destino", afirmaba La Gaceta de Buenos Aires en: ("El nuevo presidente", 1914). Por su parte, La Razón sostuvo: "no es un gobierno ideal el que nos ha tocado en suerte en medio de circunstancias acaso no tan graves como otras análogas del pasado, que resolvieron hombres de Estado, de talento y de 'muñeca” ("Tareas del gobierno", 1914).

22 Véanse, entre otras: “¿Dónde está el gobierno?”, 1914; “Desconcierto general”, 1914; “El problema financiero”, 1914 y "A la buena de Dios", 1914.

23 Otro ejemplo de ese tipo de críticas puede verse en el editorial firmado por Constancio C. Vigil a finales de septiembre ante el "penoso espectáculo de este hombre. Anciano, multimillonario y célibe [...] un muerto que gobierna". "La semana”, 1914.

24 AMREC-PGM, caja AH0016, "Guerra europea. Medidas de Guerra. Neutralidad”, legajo II A 1, fs. 8-10 y Ministerio de Marina (1915, pp. 9-10). Cabe destacar que desde comienzos de la guerra, el gobierno británico presionó a su par argentino para que las estaciones fueran directamente desmanteladas mientras los buques extranjeros permanecieran en aguas neutrales y posteriormente sugirió incrementar las penalidades contra aquellas personas que establecieran nuevas instalaciones radiotelegráficas. Ante este último reclamo, el ministro de Marina, Juan Pablo Sáenz Valiente, informó al canciller José Luis Murature que "las penalidades aplicables en estos casos están determinadas por la Ley de Correos y Telégrafos, y que, aparte de que su reforma tendría que ser motivo de un mensaje al H. Congreso, este Ministerio piensa que ellas son suficientemente severas". AMREC-PGM, caja AH0027, "Guerra europea. Beligerantes en la República Argentina", legajo II F 3, f. 51.

25 Véanse, entre otras: "Instalaciones radiotelegráficas. Los alemanes en Buenos Aires", 1914; "Violando la neutralidad. Oficina radiográfica clandestina”, 1914; "Radiografía clandestina”, 1914 y "Efectos de la guerra en nuestro país. Las estaciones radiográficas en los buques de bandera argentina”, 1914.

26 AMREC-PGM, caja AH0016, "Neutralidad", legajo II A 1, f. 11. "Flagrante violación de la neutralidad argentina”, 1914; "Neutralidad argentina. Negligencia del gobierno", 1914; "Velando por nuestra neutralidad. Comprobación de las denuncias de 'La Argentina", 1914; "La falsa neutralidad", 1914; "Nuestra neutralidad", 1914 y "Violación de la neutralidad”, 1914. En el mismo sentido, las recurrentes denuncias de la legación británica en Buenos Aires sobre el armado de los buques alemanes como cruceros auxiliares y la carga de productos de contrabando pueden verse en AMREC-PGM, caja AH0027, "Guerra europea. Beligerantes en la República Argentina”, legajo II F 1.

27 "Los náufragos del Cap Trafalgar. Confinados en Martín García”, 1914; "Los sobrevivientes del Cap Trafalgar. Actitud del gobierno argentino", 1914; "La conflagración europea. Fueron conducidos ayer á la isla Martín García los tripulantes del Cap Trafalgar”, 1914; "Los sobrevivientes del Cap Trafalgar. Serán confinados en Martín García”, 1914; "La guerra en las costas sudamericanas. Los heridos del Cap Trafalgar”, 1914 y "La tragedia del Cap Trafalgar”, 1914.

28 Véanse, entre otras: "Los náufragos del Cap Trafalgar. En Martín García. La excursión de ayer”, 1914; "Los marinos alemanes en Martín García. La visita de ayer”, 1914 y “Visita a los marinos del ‘Cap Trafalgar' en Martín García”, 1914

29 "La neutralidad en peligro", 1914 y "La neutralidad argentina y la sudamericana”, 1914. Para una descripción más detallada de ambos combates (McNally, 2012).

30 Semanas atrás, luego de recibir de su corresponsal en Valparaíso una extensa crónica del combate en el Cabo Coronel, $L a$ Argentina había titulado: "La gloriosa tradición de Nelson. Dignamente continuada", (13 de noviembre de 1914, p. 5).

31 Véanse, entre otros: "Ecos del combate en las Malvinas. El 'Invencible' en Montevideo", 1914; "El combate naval en las Malvinas. Nuevos detalles de la acción. Partida del 'Invencible”, 1914; "Cómo fue el combate naval de las Malvinas. Brillante recepción á los marinos victoriosos en Montevideo", 1914; "Llegada de la escuadra inglesa á Montevideo", 
1914; “La escuadra británica en Montevideo”, 1914; “Fray Mocho’ en Montevideo. El combate de las Malvinas”, 1914y Enviado especial, 1914. Según esta última crónica, también participaron del operativo otros dos periodistas uruguayos, el señor Buscazzo, "corresponsal fotográfico" de Caras y Caretas en Montevideo y el señor Lapido de La Tribuna Popular, además del señor Sondereguer, representante de La Nación aunque sólo el enviado del diario dirigido por Natalio Botana pudo llegar a bordo del buque, como atestiguaba la reproducción facsimilar del autógrafo enviado para los lectores de Critica.

32 Cabe aclarar que, según el Código de Presas alemán vigente, aprobado luego de la Declaración Naval de Londres en 1909, los "animales de silla, de tiro y de carga, utilizables para la guerra" eran considerados como "contrabando absoluto" mientras que los víveres y los “vestidos, tejidos para ropa y calzados, propios para uso militares”, eran conceptuados como "contrabando condicional”. AMREC-PGM, caja AH0002, "Guerra europea. Alemania”, legajo I A 5, fs. 4-6.

33 En el mismo sentido: "La manufactura nacional", 1914 y "El triunfo del poncho criollo", 1914.

34 "Junto con el mate y el poncho, cruzan el Atlántico y van a echar raíces, en los más ilustres países del mundo, dos características de nuestra idiosincrasia social, dos girones de nuestra vida, dos especialidades encerradas hasta ahora en los límites de nuestra democracia. Hay más aún: entre nosotros mismos, el mate y el poncho, asaltados por la progresiva europeización de nuestras costumbres (...) habían comenzado a desaparecer". "Mate y poncho", 1914.

35 La traducción de la carta puede consultarte en el Archivo General de la Nación, Fondo Victorino de la Plaza, legajo N. • 418, "Documentación oficial y particular (octubre de 1914)", fs. 92-98.

\section{BY-NC-SA}

